\title{
COLLOQUE INTERNATIONALE INTERDISCIPLINAIRE: La liberté à l'époque de Jacques Maritain 1931-1939
} (Institut d'Études Politiques, Université de Strasbourg, 6-7 diciembre 2012)

Durante los días 6 y 7 de septiembre se celebró en el Instituto de Estudios Políticos de la Universidad de Estrasburgo un "Coloquio Internacional Interdisciplinar" (jurídico, histórico, político y filosófico) sobre "La libertad en la época de Jacques Maritain 1931-1939”. Organizado con la colaboración de las Facultades de Teología católica y de Derecho canónico de la propia Universidad de Estrasburgo y el ayuntamiento de Kolbsheim, localidad alsaciana en la que se custodia el Archivo Jacques y Raïsa Maritain, reunió a ponentes y oyentes de diversos países europeos (Francia, Italia y España) y americanos (Colombia, Venezuela). El mérito de los profesores Jean-Louis Clément, del Instituto de Estudios Políticos, Luc Perrin y Philippe Vallin, ambos del Equipo de acogida de Teología católica y ciencias religiosas, responsables del coloquio, es enorme, tanto desde el punto de vista de la organización material del mismo, como de la calidad y oportunidad de las diversas intervenciones. El profesor Clément, Maître de conferences en Historia de las ideas políticas, es autor de una obra importante sobre la relación entre catolicismo y régimen político en Francia, en la que cabe destacar La collaboration des évêques (2011), nueva edición de Les évêques au temps de Vichy. Loyalisme sans inféodation (1999), así como Les assises intelectuelles de la République. Philosophies de l'État 1880-1914 (2006). Luc Perrin, Maître de conferences en Historia de la Iglesia moderna y contemporánea, es autor de Au service de la mission, Robert Frossard (1991) y L'affaire Lefebvre (1989). El páter Vallin, asimismo Maître de conferences y experto en Teología de la gracia, es autor de Le prochain comme tierce personne dans la théologie de la création chez Saint Thomas d'Aquin (2000) y Transcrire la Trinité. Concepts, esthétique, et esthétique des concepts en théologie systématique (en prensa).

En sesión inaugural, presentada por el director del Instituto de Estudios Políticos, Sylvain Schirmann, introdujo las cuestiones esenciales del coloquio Monseñor Aldo Giordano, Observador permanente de la Santa Sede cerca del Consejo de Europa, insistiendo en la defensa de los Derechos humanos, que se encuentra entre los cometidos de la Iglesia católica y haciendo mención de varios casos referidos a materia de libertad religiosa. A continuación, Vittorio Possenti, de la Univesidad de Venecia, disertó sobre "La finalidad de la política y la libertad en J. Maritain y E. Böckenförde”. Puso de manifiesto la conexión entre la necesidad de una fe temporal que obre como levadura de la democracia, según Maritain, y 
la problemática del Estado liberal incapaz de garantizar los supuestos de los que vive. Para el constitucionalista alemán no es secundaria la cuestión de cómo podrá subsistir un régimen liberal si la fuerza religiosa no lo sostiene. El marco de esta comunicación fue la relectura de las ricas conferencias maritenianas publicadas en 1942 como Cristianismo y democracia. Por su parte, Manuel J. Peláez, de la Universidad de Málaga, revisó el tema de la libertad en España, haciendo hincapié en la biografía intelectual de Ángel Ossorio, "el Papa de la juridicidad”, pero con alusiones también a grandes juristas como Manuel Azaña, Fernando de los Ríos, de quien destacó su visión de la Rusia soviética, Luis Jiménez de Asúa o Semprún Gurrea. Si algo puso de manifiesto la comunicación del profesor Peláez fue la enorme distancia entre el debate francés sobre la libertad en la última etapa del Renouveau catholique y la situación española, polarizada en torno al problema constitucional de la II República.

Intervinieron después la medievalista de la Universidad de Lille Agnès Graceffa, Pierre-Yves Kirsleger, de la Universidad Paul-Valéry de Montpellier y Philippe Vallin. La profesora Graceffa se ocupó del tema “¿Qué libertad en la Edad Media? El análisis de los historiadores medievalistas franceses en los años 30 con respecto a Bélgica y Alemania”. Bajo la III República francesa se produjo la mutación del ideal de libertad, interpretado por Guizot, Michelet y otros intelectuales a través de la figura del burgués. La libertad es para ellos una conquista de la burguesía, argumentación coherente con los esquemas del antigermanismo francés de finales del siglo XIX. El debate sobre las libertades medievales tiene gran peso en la obra de Pirenne, Gilson y Bloch, a cuyas obras dedicó la mayor parte de su intervención. El profesor Kirschleger, con "La libertad en los debates del protestantismo francés", estructuró su comunicación a partir de dos fenómenos característicos de los años 20, aparentemente opuestos: por un lado la Iglesia como reino unificado y por otro la cristalización del conflicto entre política y religión. En ese contexto, en el que además la izquierda protestante está próxima al socialismo y la derecha protestante, en cambio, es más cercana a las ideologías no democráticas y antidreyfussardes, crece en Francia la influencia de Karl Barth. A continuación el ponente se refirió al papel desempeñado por la revista Le Semeur, de la Federación de Estudiantes Franceses Protestantes, entre la juventud protestante francesa. El profesor Vallin cerró la sesión con una intervención sobre "La libertad en la doctrina de la Iglesia católica”. En ella destacó la importancia en este campo de los magisterios de León XIII y Pío XI. De este último destacó su labor como orientador de energías que podrían ser destructoras, liberando a la Iglesia de solidaridades peligrosas para que pueda así ejercer como "Iglesia liberadora". La comunicación se estructuró sobre tres lemas: la libertad dentro de la libertad de la Iglesia (habeas Corpus mysticum; espacio compartido por la Iglesia y el Estado; la comunión de los santos como regla paradójica de una sociedad sobrenatural); la Iglesia liberadora liberada por Cristo; y la libertad del hombre querida por Dios.

La sesión de la mañana del viernes 7 de septiembre fue presidida por el Vicerrector de la Universidad de Estrasburgo Michel Deneken. El profesor Jerónimo Molina, de la Universidad de Murcia, discurrió sobre "La querella del maquiavelismo: Jacques Maritain y Raymond Aron”, diálogo entre los dos intelectuales 
que se desenvuelve, en sus aspectos centrales, entre 1939 y 1945 . Molina hizo una introducción a la teología política de Maritain en los años 20, que desemboca en los años 40 en una teología política de la democracia. El diálogo Maritain-Aron sobre el problema del maquiavelismo arranca de una sesión de la Sociedad francesa de filosofía en el verano de 1939: en aquella ocasión se plantea la cuestión de si los regímenes democráticos deben ser capaces de las "mismas virtudes" que los totalitarios (Aron) o si, por el contrario, esta estrategia política puede transformar la sustancia liberal de las democracias europeas. La otra gran cuestión debatida fue si, en una situación de necesidad o emergencia, es posible elegir libremente los medios de la acción política. A continuación, Michel Fourcade, profesor de la Universidad Paul-Valéry de Montepellier se ocupó de "La cité libre: Maritain y el neoliberalismo". Fourcade, al hilo de su exposición sobre el famoso Coloquio Lippmann, organizado por Louis Rougier en París en 1938, estableció la discontinuidad, a su juicio palmaria, entre cristianismo y liberalismo. Precisamente en este punto se anuda la crítica de Maritain al liberalismo, ya presente en Primauté du spirituel. En suma, la propuesta de Maritain, hilo rojo de su pensamiento político, consiste en una "filosofía no liberal de la libertad", es decir, una concepción no individualista de esta.

Intervino a continuación Raphaël Kling, de la Orden de Predicadores, que expuso con gran minuciosidad el contenido del curso de Maritain en el Instituto católico de París: "Una filosofía tomista de la libertad: el curso de Jacques Maritain en el Instituto católico de París de 1936 a 1939”. Kling resaltó que este fue el último curso profesado por Maritain en Francia, pues después de la guerra, por circunstancias diversas, ya no retomó su carrera académica. Los aspectos centrales de aquel curso, consultado directamente por el ponente, son el dinamismo del libre arbitrio y la distinción entre la libertad como espontaneidad y la libertad como autonomía. El historiador Jean Chaunu, especialista en las relaciones entre cristianismo y totalitarismo en la Francia del siglo XX, se ocupó de "Libertad de lo espiritual frente a los tres totalitarismo en los medios intelectuales cristianos en Francia (1930-1940)". Su contribución revisó la posición política en esa década de algunos intelectuales cristianos cercanos a Maritain, preocupados como él por el problema del totalitarismo. Chaunu puso de manifiesto que, en ese periodo, la Iglesia francesa se sintió libre de ataduras políticas, pues de un lado es notoria la crisis de las democracias parlamentarias (señalada entre otros por Schumann, inspirado en Alexis de Tocqueville), y por otro el empuje del neopaganismo totalitario, convertido en religión de sustitución.

La sesión de la tarde arrancó con la intervención muy erudita de Michel Emmanuel, doctor en historia: "No es tomista y él sabe por qué. El caso del abad Maxime Charles (1908-1993)". El ponente hizo una clara exposición del significado intelectual del Instituto Católico de París durante los años 30, verdadero epicentro de la crisis modernista en el periodo intersecular. En 1907, contando con más profesores que alumnos, estuvo a punto de ser clausurado, pero una dirección firme y un reclutamiento muy exigente del profesorado lo evitó. El abad Charles, capellán del Sacre Coeur, se formó precisamente en el Instituto, que aspiró a ser una "Sorbona católica". Estos son los datos que contextualizan la relación del 
abad con Maritain y su diálogo sobre el tomismo. El profesor Clément hizo una exposición sobre "La libertad de Georges Bernanos (1936-1938)", retrotrayéndose a sus años de afinidad con el maurrasismo e incluso con las tesis de Valois y Sorel sobre el "mito". En esa etapa, clausurada abruptamente en 1932, cultivó el sentido aristocrático del yo. Desde entonces su opinión sobre la monarquía administrativa de Maurras se transforma: todo eso le parecerá la expresión de un totalitarismo pagano. Sin embargo, Bernanos será partidario inicialmente de la causa de los nacionales en la Guerra de España, aceptando la represión de los rojos en el verano balear de 1936. Algún tiempo después romperá sus lazos con el bando nacional, irreversible a partir de su conocida obra Los grandes cementerios bajo la luna. Ahí la libertad aparece como un regreso al espíritu de la infancia y la libertad de conciencia como un mito nórdico. Guillaume Payen, de la Fundación para la Memoria de la Shoa, trató de "La liberté selon Martin Heidegger 1931-1939”, última comunicación del coloquio. Con gran ecuanimidad, Payen se refirió a un Heidegger que siempre habitó en los márgenes del régimen: no sólo por su rectorado de Friburgo, una ciudad periférica, sino porque las elites nazis no eran universitarias.

Jerónimo Molina Cano Universidad de Murcia, España

\section{Curso Internacional de Derecho Romano: "Con- TRATACIÓN Y CiRCUlACiÓN DE BiENES: DESDE ROMA HAS- TA LOS NUEVOS INSTRUMENTOS EUROPEOS”, SALAMANCA, ESPAÑA, 4-8 FEBRERO 2013}

El Curso Internacional de Derecho Romano organizado por la Schola Serviana Iuris Romani (Academia de Derecho Romano de Chile), es un evento académico consolidado y en expansión. Si bien la iniciativa está orientada a estudiantes chilenos de la licenciatura en Derecho, lo cierto es que, por su alta calidad, ha concitado el interés creciente licenciandos y doctorandos de toda América y Europa. Sólo los alumnos chilenos asistentes sumaron la notable cifra de 116, procedentes de siete diversas Casas de Estudios; de los cuales 13 contaron con becas completas proporcionadas por la Schola Serviana Iuris Romani y dos por la Pontificia Universidad Católica de Valparaíso.

Esta tercera versión contó, una vez más, con la codirección de los profesores Dr $^{\mathrm{a}}$. Da. Amelia Castresana y Dr. D. Patricio-Ignacio Carvajal. Su inauguración se realizó en el Paraninfo de la Universidad de Salamanca, a cargo de las autoridades de mayor jerarquía, y contó con la clase magistral del Prof. Jorge Rodríguez Zapata, Presidente de la Sección $7^{\text {a }}$ de la Sala Tercera del Tribunal Supremo Español, Magistrado emérito del Tribunal Constitucional: "Un nuevo 'ius commune': la jurisprudencia constitucional sin fronteras". 